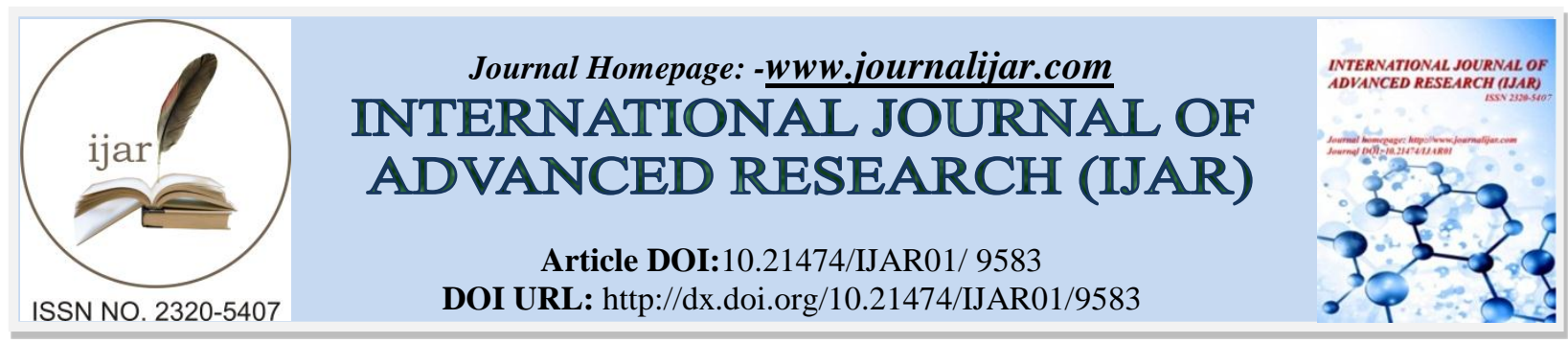

RESEARCH ARTICLE

\title{
ENERGY PLANNING FOR SUSTAINABLE DEVELOPMENT.
}

\author{
Ajith Dissanayaka. \\ Department of Economics, University of Kelaniya, Sri Lanka.
}

\section{Manuscript Info}

Manuscript History

Received: 18 June 2019

Final Accepted: 20 July 2019

Published: August 2019

Key words:-

Energy Planning, Environment, Attitudes, Sustainable Development.

JEL classification: $O_{4}, Q_{43}$ and $Q_{56}$.

\begin{abstract}
Sustainable energy planning is a pre-requisite for sustainable development. In the meantime, attitudes and technology of industrialized nations towards energy planning are not compatible with the goal of environmental sustainability. Strategies used in energy planning in many countries are traditional and do not consider much about the technological challenges that are to be addressed in energy planning at the local, national and global scales and focus only on how to optimize economic output. This paper examines how to address environmental constraints in energy planning process and to suggest suitable solutions for energy planning in order to obtain a high welfare for the global society.
\end{abstract}

Copy Right, IJAR, 2019,. All rights reserved.

\section{Introduction:-}

At present, only a few million people in the world live within cultures, which are environmentally sustainable. Over 5 billion people live in unsustainable societies, which will necessarily undergo some fundamental changes in the near future, either forced upon them by acute environmental problems or-preferably-brought about through carefully considered actions. In the light of this outlook, the industrialized countries will have to reexamine their goals for development in technology, population, economy and attitudes in general. These elements in societies must be adapted to fit within an environmentally sustainable framework.

In this paper, we will briefly describe some possible ways of addressing these new challenges and will also illustrate how energy and environmental development are closely correlated with other aspects of society. Energy is an essential area for planning, as it plays a central role in the general development of technology, economy, and the environment. It is clear, therefore, that energy planning for sustainability cannot be satisfactorily carried out if it is separated from the goals in economics, population, education, etc.

In this paper, examples are given of the environmental problems, which reflect the unsustainability of the present path in the industrialized countries. We will suggest possible ways of integrating the existing environmental limitations into energy planning. Finally, we discuss four parameters, which determine the environmental impact caused by the use of energy in the future, namely: technology, population, the economy, and individual attitudes.

\section{Environmental Sustainability}

The limits to human activities in a finite world have been discussed since the 1960s and the 1970s (Carson 1962; Goldsmith et al 1972; Meadows et al 1972; Norgard 1993; Christensen 1998). Since then, some environmental problems appear to have been solved or postponed, but new problems have emerged. Today most environmental

Corresponding Author:-Ajith Dissanayaka.

Address:-Department of Economics, University of Kelaniya, Sri Lanka. 
scientists agree that present trends in development in industrialized countries cannot be sustained environmentally for very long.

\section{Greenhouse Effect}

At present, one of the most discussed environmental problems is the global increase in carbon dioxide $\left(\mathrm{CO}_{2}\right)$ in the atmosphere. Carbon dioxide, is an inevitable by-product of burning fossil fuels, most intensively produced from burning coal and least from burning natural gas. This extra $\mathrm{CO}_{2}$ is to be considered a pollutant when emitted, because it increases the natural concentration of $\mathrm{CO}_{2}$ in the atmosphere. This higher $\mathrm{CO}_{2}$ concentration will eventually cause climatic changes through increasing the greenhouse effect and raising the average global temperature. Furthermore, $\mathrm{CO}_{2}$ emission constitutes a pollution for, which there seems to be no realistic option for cleaning at the stacks. The burning of biomass such as firewood or straw also emits $\mathrm{CO}_{2}$, but this is eventually neutralized by the equal amount of $\mathrm{CO}_{2}$ added to the overall atmospheric level. Table 01 shows recent estimates of the contribution of $\mathrm{CO}_{2}$ and other gases to the greenhouse effect. The gases in Table 01 will all certainly cause higher global temperatures than we would otherwise have. The uncertainties relate only to how fast the temperature will change, whether the change has already taken effect, and which climatic changes the increase in temperature will cause.

Table 01:-

\begin{tabular}{|lc|}
\hline Pollutant gas & Relative contribution (\%) \\
\hline $\mathrm{CO}_{2}$ from fossil fuels and deforestation & 55 \\
\hline Methane & 15 \\
\hline $\mathrm{CFC}$ gases & 24 \\
\hline $\mathrm{N}_{2} \mathrm{O}$ & 06 \\
\hline
\end{tabular}

Estimates for the relative contribution to global warming from each of the important human-caused greenhouse gases during the 1980s (Houghton et al 1990). An estimated 10\%-30\% of the $\mathrm{CO}_{2}$ contribution comes from deforestation. The numbers are continuously updated and revised. New contributors to the greenhouse effect are revealed and others, such as the CFC gases, are beginning to be phased out. In general, the overall picture shown in the table holds, with the combustion of fossil fuels as the dominant contribution to global warming.

\section{Ozone Depletion}

The list of greenhouse gases includes chlorofluorocarbon (CFC) gases. These synthetic gases can cause an additional severe environmental hazard, namely the depletion of the ozone layer in the upper part of the atmosphere, the stratosphere, where this layer shields life on earth against excessive ultraviolet radiation from the sun, In recent years such depletion, causing ozone 'holes', has been observed in several places.

CFC gases are used in many energy-related technologies, primarily as a refrigerant in cooking systems and heat pumps, and as a propellant and insulating gas in foam materials for thermal insulation. Substitutes will have to be found, as discussed in section 4.1 .

\section{Other Environmental Impacts}

Energy consumption and energy technologies cause many other environmental impacts. Sulfur dioxide, $\mathrm{SO}_{2}$, and various nitrogen oxides, $\mathrm{NO}_{\mathrm{x}}$, are some of the most discussed pollutants because of their damaging effect on forests, agriculture, human health, and buildings. The emission of radioactive pollutants, heavy metals, and certain toxic hydrocarbons are also associated with energy production. Even if these pollutants can be cleaned at the stack they still constitute a problem-as a waste to be deposited somewhere.

Nuclear power causes special environmental problems, mainly associated with the risk, albeit low, of accidents that would have extreme consequences, and with the disposal of long-lived radioactive waste. These problems, and the high cost of nuclear power plants, are the main reasons why some countries have eliminated nuclear power as an acceptable energy source.

A different kind of environmental problem is the gradual depletion of the non- renewable energy resources, which moves the extraction process to more and more environmentally fragile areas: offshore drilling, arctic exploitation, etc. 
Even the use of renewable energy resources such as biomass, wind, photovoltaic, and hydropower can cause environmental problems, although they are usually of a lower order of magnitude and of a more reversible type than those caused by non-renewable sources. Biomass resources, however, can be exploited beyond the carrying capacity of the ecosystem in question, and the resultant damage to the soil can be severe and irreversible.

\section{Sustainable Development}

The term sustainability has, in recent years, been used and abused a great deal by decision makers, often in a pretentious effort to claim that they are environmentally responsible.

Economic theory provides a definition of income, which includes sustainability. According to the British economist John Hicks, income is the maximum value, which can be consumed during a period and still leave the consumer as well off afterwards (Hicks 1939). If the externalities such as resource depletion and other environmental impacts are included in Hicks' definition of income, this is also a valid definition of overall sustainable consumption or, more generally, a sustainable development.

A more operational definition of an ecologically sustainable development, inspired by the World Bank economist Herman Daly ((Daly 1990), implies that:

1. Renewable resources (eg. biomass) should not be utilized at a rate higher than that of regeneration.

2. Pollutants (eg. $\mathrm{CO}_{2}$ ) should not be emitted at a higher rate than the natural environmental is able to absorb and neutralize them.

3. Non-renewable resources (eg: oil, gas, and uranium) should not be used.

In a somewhat 'softer' definition, economists (such as Daly) would add to (c) ' $\ldots$ at a higher rate than human-made capital can replace the natural capital lost by consuming these natural resources'. This means, for instance, that if a tone of oil is consumed and some of this oil is used to build renewable energy systems, which can provide more energy than what was lost through the consumption of the oil, such use of oil can, with the 'soft' definition, be considered sustainable. This traditional economic view requires, however, that we know the future values of all social and environmental costs and benefits, which of course we do not.

Around the world we are presently violating all three of these requirements for a sustainable development. The high use of fossil fuels is an example of violating (b) and (c), as we thereby emit $\mathrm{CO}_{2}$ at a much higher rate than the oceans and biosphere can absorb it, and we use non-renewable resources at a much higher rate than we are building up capital to replace them.

\section{UN Commissions and their Recommendations}

In 1987 the World Commission on Environment and Development published the findings of a two-year study in the report Our Common Future (WCED 1987). The 22-committee members from all over the world, led by the Norwegian Prime Minister, Gro Harlem Brundtland, came up with some rather remarkable statements. For example, the Commission strongly urges that, over the next four decades, primary energy consumption per capita in the industrialized countries must be reduced to about half the present level. Furthermore, use of renewable energy resources should be promoted in order to supply an increasing part of the remaining half. There is now, however, good basis in another UN report to assume that the Brundtland commission still did not go far enough in its proposed measures to reach a sustainable development.

This new report was published by the Intergovernmental Panel on Climate Change, IPCC, which was jointly established in 1988 by the World Meteorological Organization and the United Nations Environment Programme, UNEP, (Houghton et al 1990). In October 1990 the panel concluded that in order to stabilize the concentration of greenhouse gases in the atmosphere, the amount of global reduction would be $60 \%$ of the present level, if achieved immediately. It is, however, not realistic to achieve the necessary changes in less than a few decades. It the meantime, a higher $\mathrm{CO}_{2}$ concentration will build up, and hence the final emission reduction will have to be more than the 60\%-probably around $80 \%$ of the present level on a global basis (Houghton et al 1990). The emission of other long-lived greenhouse gases will have to be similarly reduced to avoid severe climatic changes.

An exemplary international agreement has been demonstrated on phasing out the ozone-depleting CFC gasesalthough it might yet turn out to be too little and too late to prevent severe damage. During the United Nations Conference on Environment and Development (UNCED) Earth Summit at Rio de Janeiro in 1992, the rich countries were not able to agree on any constraints on their $\mathrm{CO}_{2}$ emission. By 1993, the European Communities might agree 
on the very modest goal of stabilizing their emissions at the 1990 level by the year 2000, and with a new president in the USA, there is some hope for international and foresighted agreements on $\mathrm{CO}_{2}$ emissions.

\section{Global allocation of permissible pollution}

At present the industrialized countries are responsible for the major part of the global environmental problems we are all facing such as the greenhouse effect and ozone depletion. It is clear that the global emission of $\mathrm{CO}_{2}$, for instance, must be reduced considerably. The big question is how the future allowable per-capita emission quotas should be distributed between countries. Because of the accumulation of the earlier emission from the industrialized countries, it would seem fair to allow the developing countries to emit more per capita than the industrialized countries for a period of time. A politically more realistic principle for the future, however, could be to allocate the allowable global environmental loads on equal per-capita basis all over the world. It could, however, be argued that the basis for this allocation should not just be any future population, but rather the present population, in order to encourage an environmentally responsible population policy.

Without going into great detail about the various pollutants, we can see that the above suggestion would call for an equal allowable $\mathrm{CO}_{2}$ emission per capita of no more than $200 \mathrm{~kg}$ per year from the energy sector. For a country such as Denmark this would imply a $94 \%$ reduction of $\mathrm{CO}_{2}$ emission over $40 \%$ years (Brinck et al 1992).

\section{Integrated Environment and Energy Planning}

To transform the industrialized societies from the present unsustainable state to a sustainable one is a tremendous challenge. Despite the urgency of solving some of the environmental problems this cannot realistically be achieved within a few years. Long-term planning for the transformation should nevertheless be established as soon as possible and used as guidance for immediate actions in order to get on the right path towards sustainability.

Long-term planning reaches at least a couple of decades into the future. When we consider the changes required for the transformation to sustainability, it is essential to start such planning with an open mind. What are the ends we want to achieve, what are the constraints, and what are the means available? Between the means and the ends it is important to fully investigate and illuminate the various realistic choices available, which can then be subjected to a democratic decision regarding, which path to follow toward sustainability. The following suggests a model for the process of planning for sustainable energy future.

\section{Model for Planning}

Figure 01 illustrates the basic concepts and the overall procedure for an integrated energy-and-environmental plan. The central element in the planning is the creative process of building scenario. A scenario is a picture of the future, which is internally consistent in the sense that no contradictions prevent the scenario from becoming a reality. In our simple model the main output, which illustrates the scenario are the energy consumption and its environmental impact. As seen in Figure 01, their or four variable inputs are used to build a scenario for a future year. The anticipated input for that year are: (a) the environmental impact intensity of the technology, (b) the population in the region, and (c) the energy service level (or standard of living)- which is determined by the economy and the general attitudes.

The planning process is iterative and can be summarized as follows. A first scenario, to be used as a reference for the subsequent scenarios, can be built from the government's outlook for technology, population, and economy, if such information is available for the future year to be considered. The impact of people's attitudes is usually given a low priority in such a government outlook, but we will return to the importance of attitudes later in this paper. Mainly the level of energy efficiency in the future year should illustrate the level of technology. In the model, the efficiency is expressed by its reciprocal value, the energy intensity, I, define as the energy required per output of energy service. In this first reference scenario the level of efficiency is based on the assumption that no special effort is directed toward improving that technical aspect.

Population, $\mathrm{P}$, is essential in long-term planning for sustainability. Official prognoses or targets for population development can be used in the reference scenario. In the reference scenario, the official economic outlook (if one exists for the future year considered) should be transferred into a set of corresponding energy services. This energy service level is noted by $\mathrm{S}$ in figure 01 , and is described in more detail in section 3.2.

A first scenario-a reference scenario-can now be established on the basis of these inputs. Its energy consumption will, with these 'business as usual' input, often be similar to the consumption described in official energy plans or 
energy prognoses. Some environmental consequences can be derived from the energy-demand data in the scenario with the assumption that there is no change in the mixture of energy sources used and that no new measures are taken to reduce emission at the stacks.

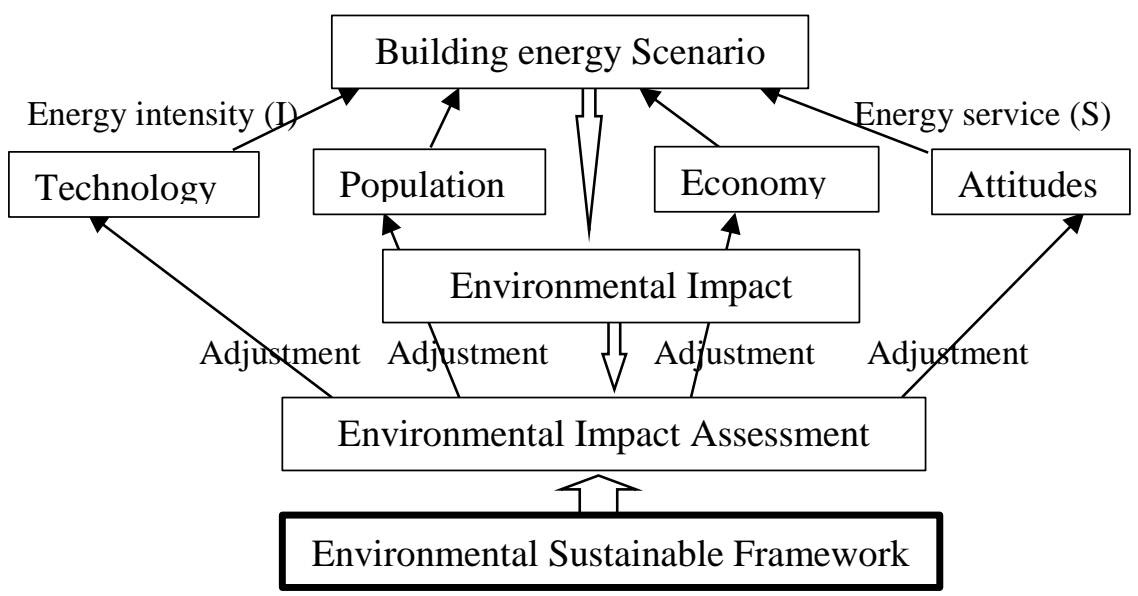

Figure 01:- Overview of the concepts and procedures, which are involved in our model for an integrated energy and environmental planning process, based on iterative scenario building. The environmental impact from the resulting energy consumption is compared to the environmentally sustainable level, and adjustments are made.

The next step is to compare the environmental impact of the reference scenario with the critical or permissible loads of sustainability, locally as well as globally. It is most likely that this first scenario will turn out to be highly unsustainable, and a second scenario is built with the inputs adjusted toward sustainability. For technology, higher energy efficiency is one of the key variables to be adjusted (see later). A more active population policy can be considered necessary to reach a certain level of sustainable welfare. Finally, at a closer look, the anticipated future level of material welfare might be too high to be sustained. In that case, the economic practice and structure, as well as the general attitudes toward material consumption, have to be adjusted to be less wasteful in the second scenario, in order to approach a sustainable future. The iterative process continues with the adjusted scenarios until one, or (preferably) more, of the scenarios illustrate paths to reach sustainability. In the following we will elaborate a little on one the central elements in the model, the concept of energy service.

\section{Energy Service}

A classic mistake in energy planning is to assume-often subconsciously that energy consumption is a measure of welfare. This is particularly unfortunate when planning for the long term. Energy excluding food is of no direct value to human beings. Oil, coal, gas, uranium, petrol, electricity, etc. cannot be consumed directly. They are useful only as inputs to technologies, which then provide services as their outputs, such as warm meals, convenient transport, comfortable rooms, illumination at the desk, and clean clothes. These energy services are what can directly contribute to human welfare. The amount of energy input needed to provide the service depends on the energy efficiency of the technology involved, such as stoves, houses, trains, lamps, and washing machines. Figure 02 illustrates the energy chain of technology involved in transforming the primary energy sources into energy services. Fully understanding that the energy services constitute the real measure of welfare, rather than the energy itself, is one of the most important prerequisites in energy planning for sustainability. 


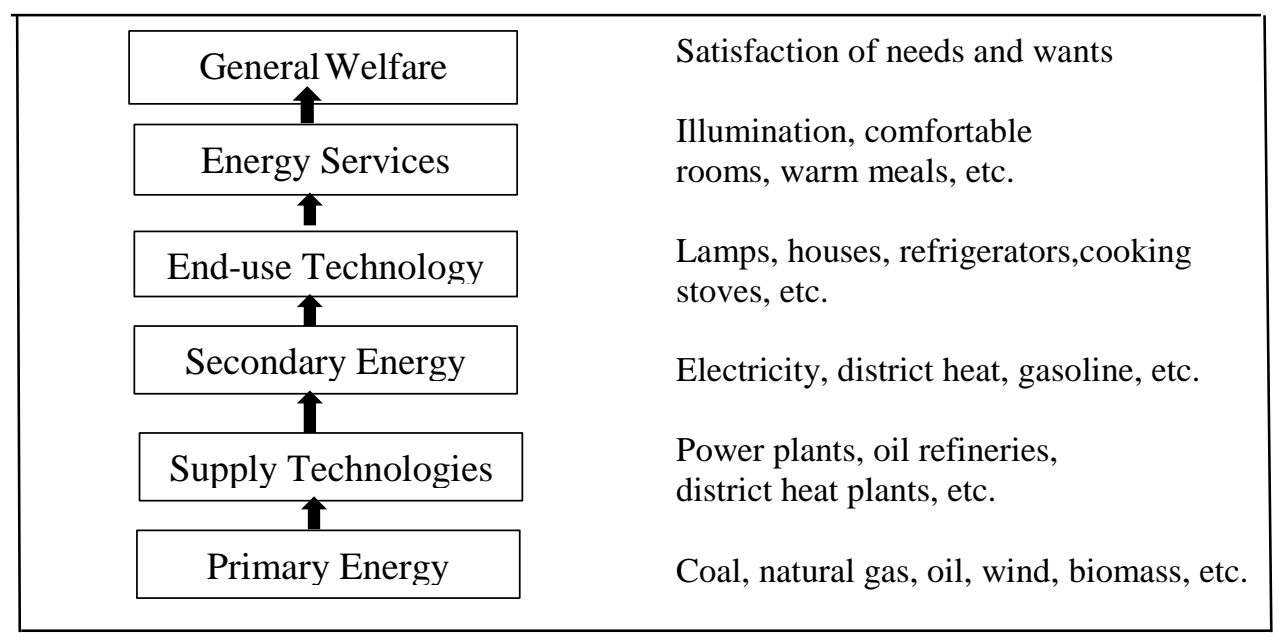

Figure 02:-Illustration of the energy chain of technologies involved in converting primary energy into energy services and welfare. The chain can be divided into end-use technologies and supply technologies, each of which many contain many components.

The various energy services cannot usually be measured in energy units and not even in the same physical units. Hence, they cannot easily be combined into one single indicator of energy service. Additionally, a dimensionless number cannot describe the efficiency of the end-use technology. These characteristics have probably led many natural-science oriented energy researchers to ignore the efficiencies of end-use technologies in fervor of the more easily quantifiable efficiencies of the supply technologies.

Planning models that focus on the concept of energy service have been used in projects for environment and energy demand in the Nordic countries (Brinck et al 1992), and for Western Europe's demand for electricity in the future (Norgard and Viegand 1992). Despite an anticipated use of highly energy efficient technologies, there are clear indications that the economic growth expected by governments cannot, in the rich countries, be sustained environmentally in the decades to come (Norgard and Viegand 1992; Benestad et al 1991).

In this paper we will not go into further details about the planning technique, but instead shall discuss the content and outlook for the four determining factors in an environmentally sustainable energy future. The four factor are (a) technology, (b) population, (c) the economy, and (d) attitudes.

\section{Technological Options and Limitations}

The energy supply technologies, shown in the lower part of Figure 02 can be improved considerably, both in terms of making them more efficient in the process of converting primary energy into secondary energy, and in terms of designing them to use renewable energy sources. Additionally, the environmental impact from the energy supply can be reduced through technological cleaning efforts. In this paper, however, we will focus on the end-use technologies and the many possibilities for improving their efficiency.

Several studies have shown that there is an enormous potential for an improvement in efficiency. In theory the potential seems unlimited in many cases. For example, around 35\% of energy consumption in industrialized countries are spent on the passive task of just maintaining temperature differences. This includes keeping the interiors of houses warm in a cold climate, or cool in a warm climate, or keeping refrigerators or freezers cold in a warm environment. If thermal insulation were perfect, such tasks would require no energy consumption. Similar theoretical considerations can be applied to energy used for transport and for temporary changes in temperature, such as those used in many industrial processes. In real life however, there are limits to the technical potential for conservation of energy. It is estimated that over a twenty-year period the efficiency of new end-use technology can be improved by a factor of around three (Norgard and Viegand 1992). In other words we can enjoy the present energy service or material standard of living with just one-third of our present consumption of secondary energy, or we can triple the energy service output without increasing our consumption of energy (Goldemberg et al 1988; 
Danish Ministry of Energy 1990). In this paper we will illustrate the potential for efficiency improvement with just a few examples from the use of electricity.

\section{Electricity use as an example}

Electricity is used for hundreds of different tasks, most of, which play a relatively insignificant role in the economic budget of the home, institution industry, or wherever electricity is used. For that reason, saving options have often been ignored, even though electricity accounts for around $25 \%$ of the worldwide use of primary energy, and the proportion is growing fast. The following examples will illustrate the vast potential for saving in electricity.

A very efficient refrigerator has been developed and was marketed in 1988, see Figure 03. The 2001 unit consumes only $90 \mathrm{kWh}$ per year, or around 25\% of what is typical for refrigerators in use (Guldbrandsen and Norgard 1986; Brdr Gram A/S 1990). Although this refrigerator was first designed with ozone-depleting CFC gas in the insulation from and as a coolant, the relative energy saving achieved is not associated with the use of CFC cases. In 1993 this electricity efficient refrigerator is available as a CFC free version. Still higher electric efficiencies can be achieved for refrigerators, as shown in Figure 03.

New light sources, compact fluorescent light bulbs, are three to four times as efficient as the normal incandescent light bulbs. Control systems, better lamps and fixtures, etc can also contribute considerably to making lighting more efficient. There are examples of electricity consumption for lighting being cut to less than $20 \%$ of what is commonly used today.

Ventilation systems can also be designed to provide the same indoor air quality with only a small fraction of the electricity that is used present systems, typically 15\% (Norgard 1989; Larson and Nilsson 1990). More references and examples of improving electric end-use technologies are described by Horgard (1989) and in the various reports from the Competitek Institute (Lovins and Sardinsky 1988; Lovins et al 1989; Shepard et al 1990; Houghton et al

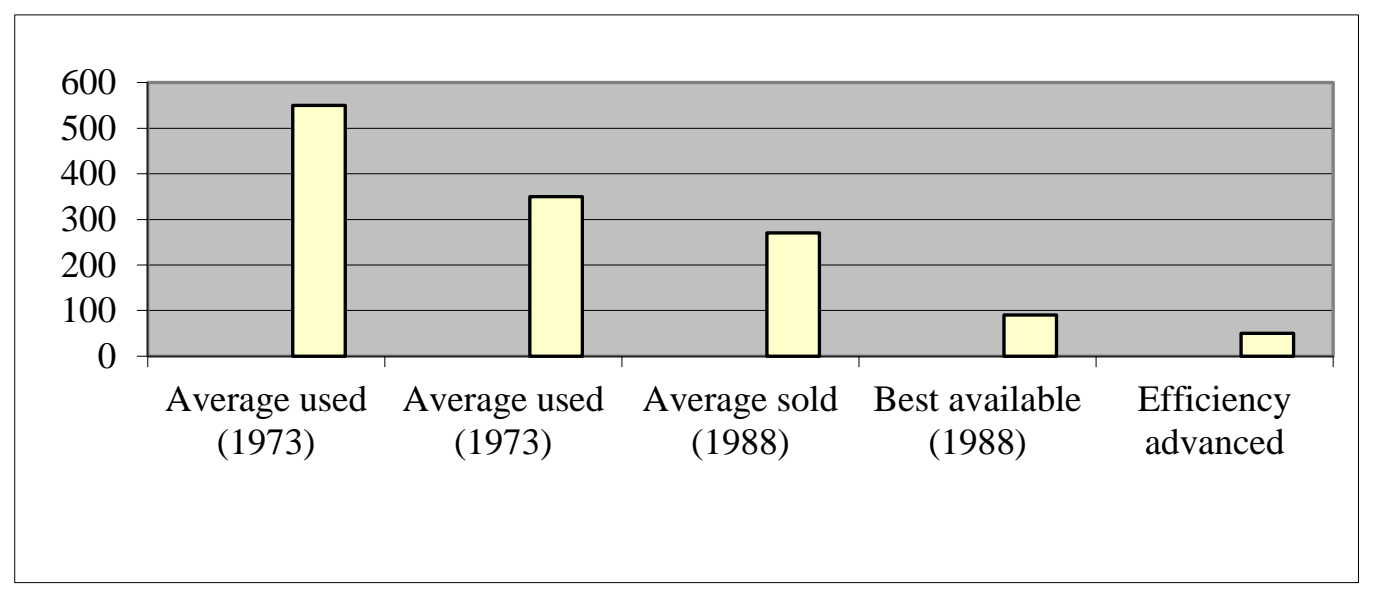
1992).

Figure 03:-Electricity consumption at European standard test conditions $\left(25^{\circ} \mathrm{C}\right.$ outside, $5^{0} \mathrm{C}$ inside $)$ for various versions of a 200-liter refrigerator with no freezer compartment. The intensity index, I, on the scale to the right illustrates the relative improvements, and is approximately transferable to other sizes of refrigerators, to freezers, and to combined units and commercial units in shops (Norgard 1989).

\section{Costs of Saving}

To save one unit of energy through more efficient end-use technology is today much cheaper than to produce one unit of energy. This is particularly the case when the improvements are introduced in the course of natural replacement of existing energy consuming capital, as assumed in the following discussion. Many studies find rather low potentials for cost effective saving through more efficient technology, usually because the studies are more or less based on a costly, immediately forced replacement of an existing system. For a long-term policy, i.e. 20-30 years, such methods for estimating saving potentials are rather irrelevant, since most capital will be replaced within that time horizon. 
Another pitfall in cost estimates of new energy saving technology is to assume that the price reflects the production cost. This is the case only in a perfect free market with many independent and competing manufacturers, and with full information available to the consumers. In the long run a higher price might reflect the extra cost, but in the first years after introducing a new energy-saving technology the price charged is often determined by the manufacturer's expectations of what kind of payback time the consumer will be willing to accept. The cost of saving energy also depends on what has already been done in this area. The more that energy is saved, the more expensive it becomes to save another unit-if we assume that the least expensive options are used first. Figure 04 illustrates this rising marginal cost of saving a $\mathrm{kWh}$ of electricity, as compared to producing a $\mathrm{kWh}$. It is estimated, as illustrated, that more than half of the present consumption of electricity can be saved with cost-effective technological measures. Only thereafter will it become more costly to save than to produce electricity. Considering the environmental benefits of saving as compared to producing, we should not hesitate to go beyond the limit of traditional economic cost-effectiveness. We should be prepared in one way or another to pay something for better environment. In the long run, however, the environmentally benign policy of saving energy will often also be the most cost-effective energy policy. This was reflected in the Danish governmental plan 'Energy 2010'. The scenario with high emphasis on energy efficiency turned out to be less expensive than the reference or 'business as usual' scenario (Danish Ministry of Energy 1998).

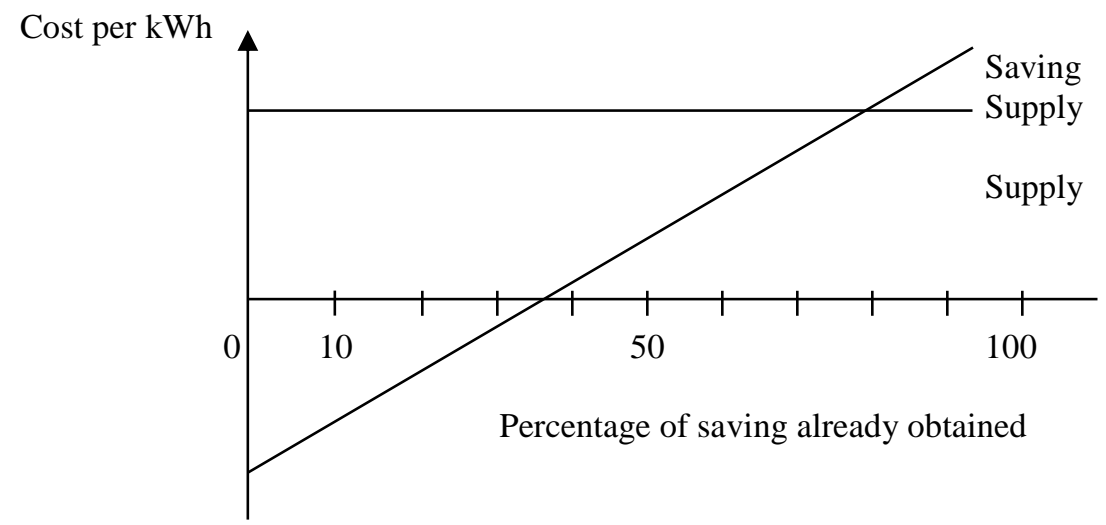

Figure 04:-Cost of saving and cost of supply. Saving a kWh of energy is generally much less expensive than to supply a kWh as illustrated to the left in the diagram. Yet the cost of saving another kWh of energy become more expensive as more is saved. This marginal cost of saving is qualitatively illustrated here. At a certain level of saving it becomes more expensive to save than to supply energy, but more than half of the energy consumption in a typical industrialized country can be saved before reaching that point.

The fact that energy saving is cost-effective implies that the strongly-needed economic development in some parts of the world, particularly in Third World countries, can be accelerated if a higher priority is given to investment in more efficient end-use technology than in energy supply technology. Frequently, the type of scale of the efficient end-use technology is better suited for industrial production in the developing countries than large-scale power plant technology.

Despite all the economic, environmental, and social advantages, the energy-efficient technologies will not penetrate the market on their own, at least not at an acceptable rate. This reflects a lack of information on the part of decision makers and consumers and an attitude, which favors large-scale complex technology (see later). It also reflects a large amount of vested interest on the part of shareholders, employees, and engineers in energy supply technology. It will require a very determined sustainability policy to secure the future implementation of efficient end-use technology.

\section{Technology by Itself is Inadequate}

The technical options described above for using energy more efficiently are numerous but not fully recognized. However, even these technical fixes are not adequate to secure a sustainable energy future, if we otherwise continue with 'business as usual'.

One paradoxical aspect of focusing just on improving the technical efficiency is that efficiency can be accomplished by increasing energy consumption. For instance, if a family replaces their house with a larger house that is fitted 
with the same standard of insulation, indoor comfort, etc. the larger house will use less heat per square meter of floor space, because the ratio between the heat-losing surface and the surface, which provides floor space is reduced. Therefore, in accordance with normal technical practice, the house would be considered more energy efficient, even though it consumes more energy. Similarly, a large refrigerator unit will-everything else being equal-consume more electricity than a small one, but nevertheless also be technically more efficient in terms of electricity consumption per unit volume of storage space. In transportation the paradox also holds. To drive long distances will obviously require more fuel, but usually produces better efficiency, when measured as fuel consumed per km traveled.

These examples are not just accidental paradoxes. They illustrate a general view, which dominates today's energy policy. It is unfortunately considered acceptable to increase energy consumption as long as the output-the energy service-grows even faster so that efficiency increases. The absolute limits to the acceptable global energy consumption, expressed by $\mathrm{CO}_{2}$-emission and other environmental factors, make this fixation on efficiency an obsolete view on energy conservation.

In the materialistically rich industrialized countries, we must now think in terms of combining efficiency with sufficiency. An ever-growing demand for energy services will, over a period, override the environmental advantages, which efficiency improvements could otherwise have provided if we stopped the material growth at a sensible level (Norgard 1974). With an open mind we must discuss the other variables that determine the environmental impact. What could be a reasonable population and what could be reasonable objectives for a material standard of living, expressed for example as a per-capita energy service level?

\section{Population, Lower is better}

Each country should consider its population policy in the environmental perspective of sustainability. The only serious attempt to do this, so far, seems to have been in China (Keyfitz 1984). Even this exemplary policy of China might turn out to be insufficient in light of the global environmental problems we are facing today. In any case, a laissez-faire population policy seems irresponsible. It is now recognized that the traditional view on population policy, that an increased standard of living will automatically halt the population growth, is not going to work in many of the poorer countries. They are caught in what is termed the 'poverty trap'. This implies the dominance of the inverse causality, namely that improving the standard of living will require a reduced population growth. Otherwise the national economic growth is outweighed by the growth in population, resulting in no actual progress or even a decline in welfare or gross national product (GNP) per capita.

The population explosion in a region has historically occurred when economic and technical development has resulted in a rapid decline in death rates, while people still maintain high birth rates for a generation or two because of tradition, lack of information, lack of contraceptives, etc. Later, a low birth rate stabilized the population. Europe managed this transition of population explosion without too much peril, in part by migrating to, and conquering, other continents. It is worth keeping in mind that this option is not available for the poor, overpopulated countries of today. They are caught in the poverty trap, a condition, which calls for other population policy measures such as family planning progremmes, social security, guaranteed old age pension, provision of roles other than childbearing for woman, availability of safe and effective contraceptive, and a campaign for the acceptance of their use.

Not only should the developing countries be concerned about population problems. The industrialized countries in Europe are among the most densely populated areas in the world. Together with the general high standard of living, this population density puts a high pressure on the natural environment. It is encouraging that population is not presently growing in this part of the world, and in fact in some industrial countries it is declining. While this is advantageous for sustainability, the declining population is unfortunately often considered a problem by governments, mainly because of a shortsighted narrow focus on increasing the GNP.

Population policy is a very emotional and politically sensitive issue, and we will not go future into details here, except in emphasizing the extreme importance of the issue in a policy toward sustainability. The more people there are in a future world with limited sustainable energy options, the lower will be average material standard of living.

\section{Economic Growth as a Transition}

Economic growth, measured as the annual increase in GNP or gross domestic product (GDP) has historically been used as an indicator of the general welfare in a country. Today, increased GDP per capita is a very poor indicator of improvement in many industrialized countries. The material benefit of higher production and consumption is found 
to be outweighed by (a) the social cost of crime, drug addiction, etc., (b) the individual cost of loneliness, alienation, distress and associated diseases, etc., and (c) the environmental cost, which is a local and global threat.

Consequently, in order to reach environmental sustainability, it is worthwhile to consider adjusting the economic growth scenarios usually anticipated by government. In high consumption industrialized countries, the development should, for the sake of the human

and the environment, be focused on qualitative improvement in the economy and in everyday life, rather than on increasing material economic growth. We have already illustrated how a lower consumption of energy can result in a lower GDP and still provide the same energy services. Furthermore, the materialistically define energy service level is, like GDP, not necessarily a good indicator of welfare and quality of life. The end of growth in GDP is not the end of the world. An economy, which is in a steady state at a macro level, can, at a micro level, develop with just as much competition, growth, decline, and other dynamic changes as do the present growth economies.

\section{Temporary Growth}

Most economists and policymakers act today as if economic growth must and can go on forever. They are blindly chasing the maximum, rather than searching for the optimum size of the economy. They pursue this course they are often forced to work within a rather short time horizon and because they do not fully perceive the long term environmental repercussions. Their ancient idols, the pioneers in economic theory, such as John Stuart Mill, Karl Marx, Friedrich Engels, Adam Smith and John Maynard Keynes, had a wide and long-term perspective. Hence they usually considered the economic growth period as a temporary phase, a transition to a state where the economic problems of human were solved, and we could all enjoy the fruits of the technical development in a spiritually richer life (Mill 1900; Keynes 1931; Daly and Cobb 1989). This economic state seems to have been reached for the average person in many industrialized countries. But the political determination to continue further growth still dominates economic politics.

More recently, some economists such as Daly at the World Bank have pointed out how unrealistic and irrational it is to pursue economic growth as a primary goal (Daly and Cobb 1989). Also two Nobel Prize winners in economics, Jan Tinbergen and Trygva Haavelmoe, have separately stated very cleary that economic growth in the rich countries must stop, the sooner the better, if the developing countries are to have a chance of a decent material standard of living in a future world with sustainable development (Vermes 1990; Tinbergen and Hueting 1991). Even if we consider only the economic and material aspects of welfare, we see that they are no longer very well represented by the GDP. Extending the lifetime of durable goods, reuse of components, and recycling of materials are example of economic policies, which might lower the traditional GDP, but would benefit the environment without impeding welfare, just like the more efficient use of energy mentioned earlier. Another area where GDP does not reflect welfare is in leisure time. Several surveys in Europe point toward a higher preference by wage earners for more leisure time over more income, given the choice, as described later (Norgard and Christensen 1984). Such an increase in welfare in the form of more leisure time would not show up as a higher GDP either. Finally, a more equal distribution of wealth and income would increase the total welfare obtained from a certain GDP. Consequently, a high degree of equity should be a basic element in a policy aimed at a sustainable economy. The declining marginal benefit and the increasing human, social, and environmental cost of continuing economic growth have even turned some top politicians away from economic growth as a goal. Oscar Lafontaine, who was the Social Democratic chancellor candidate in Germany in the 1990 election, is one of them (Lafontaine 1985).

The above illustrates how the economy, just like technology, can be made more efficient in providing welfare. This implies that better welfare could be provided with a lower GDP, which can constitute one important step toward environmental sustainability.

\section{Poor Arguments for Economic Growth}

An obviously valid argument for increasing production is that the products are necessary for improving the standard of living. This is the situation in developing countries, where material goods such as food and decent housing are in short supply, as has earlier been the case in the presently rich countries. In affluent societies, such as in Northern Europe, the situation today is quite different. In these regions it is interesting to observe that the need for more products is hardly used as an argument for economic growth. Growth is still promoted, however, but as a means to solve, postpone, or move problems, such as unemployment and inequities in incomes and wealth. These problems can, however, be solved on other ways if the political will is there. 
To be very brief, an environmentally responsible way to solve unemployment in an affluent society is to adjust working hours to the need for labour force, which could result in a working week of 50, 40, 30, or 20 hours. Such an adjustment makes more sense than a policy to increase an already environmentally straining production. Furthermore, the policy used in the recent decade to solve unemployment by increasing production has not been convincing. In Northern Europe the growth in industrial production does not in general create more jobs. This is explained by the fact that larger production is usually achieved through investment in labour saving technology. Furthermore, if increased production reflects a gain in international of national competition with other producers, then the consequence is a loss of jobs in some other place that has relatively lower competitiveness.

The question of distribution is a very central issue in an economy moving toward sustainability, even though it is hardly ever mentioned. It is therefore interesting to see that one argument for economic growth, which can be found can in economic textbooks, is that growth will prevent a social unrest, which would otherwise be the result of inequity in a society. When the poor are better off year by year they tend to accept that inequity remains the same or even grows. This argument for growth is also mentioned in a report about the challenges in developing countries, where there seem to be more valid arguments for growth (south Commission 1992).

A reverse argument is also put forth, namely that the inequities are necessary as a spur to economic growth. In other words, growth and inequities support each other, and when sustainability calls for a slowdown and an eventual halt in economic growth, then that argument for inequity disappears.

With the recognition of environmentally limited potential for production in the world, the question of distribution become more acute, whether referring to distribution of work, income, or wealth. A democratic political answer is likely to point toward more material equity than there is today. The argument for growth as a means to make inequities acceptable originated in a time when the natural basis for economic activity was perceived as unlimited. This argument is irresponsible in an economy aiming for sustainable welfare.

\section{Attitudes for Sustainability}

As early as 1972 the executive committee of the Club of Rome stated in the report The Limits to Growth the wish “.... That man must explore himself-his goals and values-as much as the work he seeks to change". (Meadows et al 1972). In a twentieth anniversary follow-up to this report the same authors emphasize even more the need for basic changes in attitudes in order to reach a sustainable development (Meadows et al 1972). The environmentally determined decisinmakers need to reconsider and adjust some of the basic social values and attitudes in the industrialized countries.

\section{Values and Attitudes}

By values we mean the often subconsciously held fundamental beliefs on, which one's way of life is based? Examples of values to illustrate the concept are: freedom, collectivism, individualism, orderliness, traditionalism, and equality. They represent emotions and are often determined in early childhood and held for a lifetime. An attitude is usually a more conscious concept, and directed toward a specific situation.

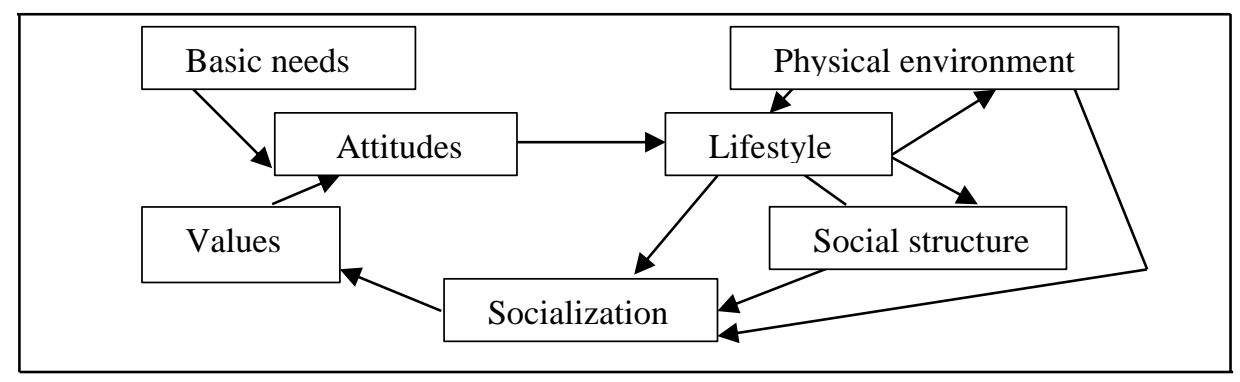

Figure 05:-Diagram illustrating how values and attitudes are shaped by the social structure (Christensen and Norgard 1976).

Values and attitudes are not changed overnight. They are shaped during the entire process of socialization, see Figure 05. Upbringing in preschool age often creates the emotional value pattern, which constitutes the base for the rest of one's life. More concrete values and attitudes are imposed during the formal education period in school and 
other institutions, as well as through television and other media. Value changes are discussed elsewhere (Christensen and Norgard 1976).

People's attitudes and social values determine how they behave within the physical framework provided by nature, economy, technology, etc. However, the human-made structures are established and developed according to the attitudes of the people in control of designing them, In an ideal democracy this control is held by the public in general and their elected representatives. But in the real and complicated world of today, the experts in technology, economics, etc. often hold the key to decisions, and it is their attitude towards the environment, technology, distribution, etc., which can and does play a dominant role.

\section{Present trends in West European attitudes}

There are many indications that people in the affluent, industrialized countries are slowly changing their attitudes away from what has been the foundation in generating the high level of material wealth. Materialism is gradually being replaced by post materialistic values and attitudes. Typical trends are that work and even the economic standard of living play a smaller role than thirty years ago. These are also some of the trends in attitudes required to approach a sustainable welfare.

One of the better illustrations of trends in attitudes is provided by a systematic series of opinion polls of 2000-4000 people in Denmark by the Danish National Institute of Social Research, in 1964, 1975, 1987, and 1999 (Kuhl and Koch-Nielesen 1976; Kuhl 1980; Platz 1988 and 2000). These surveys make it possible to look at the development of attitudes over time. One of the questions asked be: "If you had the choice between one extra hour of leisure per day (same income) and one extra hour's pay (same working time), which one would you prefer?"

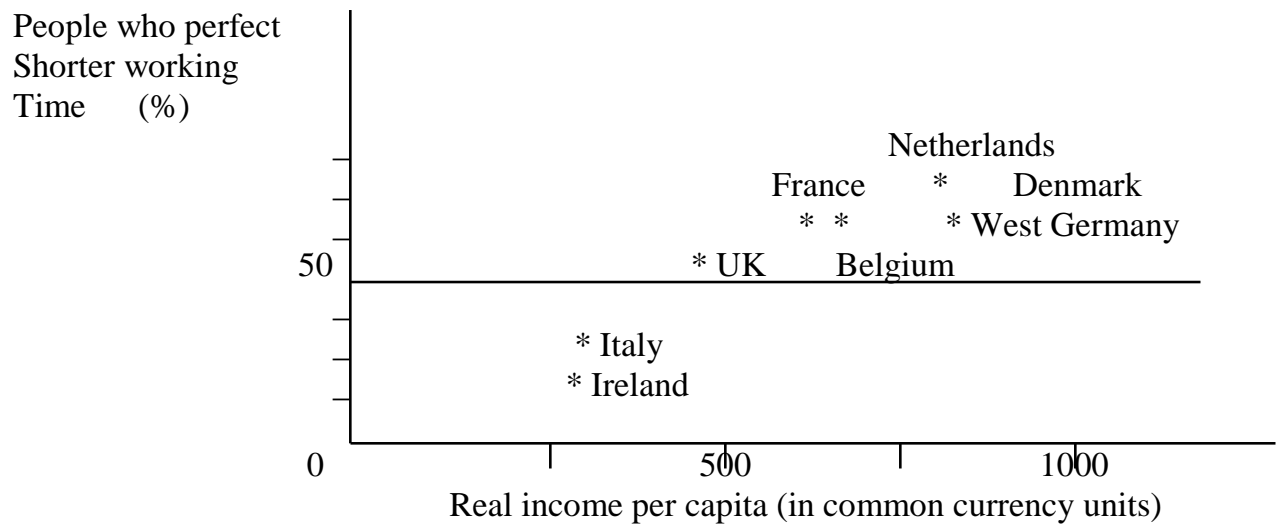

Figure 06:-Percentage of wage earners who prefer a shorter working time to more pay, as a function of income and country in 1997 (Clutterbuck).

Similar trends have also been noted in Norway. In 1992, 58\% of those interviewed preferred shorter working days over higher income, according to a relatively small sample survey taken by telephone. Another survey, in 1987, indicated that $76 \%$ found the standard of living in Norway too high (Norgard and Christensen 1994). Figure 06 shows some results of an opinion survey carried out in the EEC in 1997 (Clutterbuck 1998; OECD 1999). The question posed was almost identical to that in the Danish survey:

"Supposing the economic situation changed for the better and it become possible to think of improvements in living conditions, which of the two possibilities would you personally think the best?

1. Increase in pay 8 for the same hours of work)? or

2. Shorter working time (for the same pay)?"

The results shown are for what is termed the 'working population', but the survey showed no significant differences when the rest of the population was included. For all countries taken together, $51 \%$ of the working population surveyed preferred shorter working time, while $42 \%$ chose more pay. From the results in Figure 07 we suggest there is a correlation between the preference for more leisure time and the level of income. In most of the countries in Figure 07, the majority favored increased leisure. For Denmark this option was chosen by $66 \%$ of the working 
population surveyed, while only $26 \%$ preferred more pay, which is in good agreement with the Danish survey, as shown in Figure 06.

We interpret these surveys (along with other indicators not discussed here) as indications that attitudes in some of the high-income countries are already prepared for a saturation economy, which is a prerequisite for a sustainable future.

\section{Saturation Promoting Factors}

We will try to suggest briefly what we think is responsible for the appearance of these attitudes in Scandinavia in the year 1970 and 2000 period.

The standard of living in Scandinavia, one of the higher in the world, is obviously one important factor, as indicated in Figure 07. The higher the standard of living obtained, the less there can be gained from further increases, and eventually the marginal cost in the form of work time, etc., comes to be perceived as higher than the marginal benefit.

Distribution of income and wealth is rather even in Scandinavia, which could contribute to the presence of these attitudes. Even though there are significant differences in income and wealth in Scandinavia too, the inequalities are considerably smaller than in most industrialized countries.

For decades the Scandinavian countries have provided a high level of social welfare in the form of free education and health care, unemployment pay, and a guaranteed retirement pay for everyone. For most Scandinavians this has produced so deep a feeling of economic security that they have been able to take these benefits for granted. If they had to provide for themselves and their families in such way as to guarantee this range of socioeconomic security, there would be almost no limit to how much wealth they would want to accumulate.

The high standard of social welfare is partly responsible for the high tax level in Scandinavia. The average marginal income tax in Denmark is approximately 50\%, which makes the marginal disposable income (from employment) for the individual rather small. For example, this high marginal income tax rate, compounded with sales taxes, means that the average Danish car owner must work between five and ten days per month in order to pay for and for operate a car (Norgard and Christensen 1992). Such effects no doubt help to explain why so many people prefer more leisure to more income.

Finally, the role of women in society can help us explain some of the trends. In the surveys for Denmark made in 1975 (Figure 06), in, which 57\% of all wage earners preferred less work, the percentage of female wage earners who preferred less work was $62 \%$ and for males this was $54 \%$. This would seem to be further evidence that the values, which support a saturation economy are those traditionally considered female. And in fact women do seem to be playing a greater role in shaping society in Scandinavia than in most other industrialized countries. In the 1990s women made up more than $42 \%$ of the labour force in Denmark.

Modern government in any country does not encourage trends such as those described above, because the politicians are still promoting economic growth. Very slowly and cautiously the Danish government, for instance, is reversing most of the factors, which promote these attitudes for saturation and sustainability. Social security has been lowered, income equity reduced, marginal taxes reduced, and advertisement to encourage more consumption has increased dramatically and has recently been allowed to be shown on television.

While economic growth is needed in the developing countries, saturation in economic and material development should be encouraged in the industrialized countries, particularly in those with the highest economic standard of living. Examples of values to

be promoted or encouraged for the upcoming generation are equality, sharing and leisure, while competition, material comfort, and work should be somewhat de-emphasized. But it is all a question of balance, as described elsewhere (Christensen and Norgard 1976).

\section{Attitudes Directly Related to Energy Policy}

As mentioned earlier, the attitudes of the people directly in charge of energy policy will of Courses have a very profound and immediate impact on the choices in that area (Norgard and Christensen 1992). 
There is no doubt that energy conservation through the use of more efficient technology is preferable over more energy supply, as described earlier. Nevertheless, the policy is not being pursued very vigorously in any country. Some of the most severe barriers for this first step in a sustainable energy policy are psychological in nature, reflecting the attitudes of the decision makers.

For engineers there has also been the traditional view that there is less glamour and less prestige associated with electricity-saving technology compared with the building of large power plants, windmills, or other spectacular electricity supply systems. The engineering skills required for developing electricity-saving systems have a more holistic and interdisciplinary character than traditional engineering expertise. These skills have only recently emerged and begun to be recognized and estimated. The electricity-saving technologies can be just as sophisticated in their modest, interdisciplinary, and integrated way, as the dominant, large-scale supply technology.

Also, with their natural science background, engineers generally prefer exact definitions and achievements, which can be measured. Total efficiency in the energy, chain from primary energy to human welfare, as shown in Figure 02, cannot be defined precisely in numbers. The efficiency of converting coal into electricity can be measured precisely and given as a dimensionless number. Efficiency (or rather the reciprocal intensity) in the higher stages, the end-use technology, can possibly be expressed quantitatively, but in various units, such as in liters of gasoline per $100 \mathrm{~km}$ for a car and in GJ a $\mathrm{m}^{-1}$ of heated floor space in housing. Because the units are different, the data cannot be combined into a single number, which represents the efficiency of a household, an industry or a nation.

Such difficulties in measuring the achievements in precise numbers might make the challenges less attractive to traditional technologists, leaving behind huge potentials for saving energy.

Economists and politicians-like engineers-often prefer to deal with aspects, which can be easily expressed in numbers. Furthermore, the monumental aspect of large-scale energy technology, such as a big power plant, attracts the politicians as symbols of achievements. Energy conservation and sustainability is not nearly as spectacular in the news media. This might subconsciously give these goals a lower priority in the mind of a traditional politician.

Altogether, new attitudes are needed for those directly in charge, as well as for the public in general, if we are to reach a sustainable welfare. Such changes are usually very slow, and might constitute the most severe barrier for solving the acute environmental problems in time.

\section{Summary and Conclusion:-}

Integrated energy and environmental planning will no doubt be an essential element in future policies when it became clear that the natural resources and the environment will constitute the real constraints on development. The present way of life in the industrialized part of the world cannot be sustained for many more decades, and dramatic changes will be needed. At the same time, it is crucial that the rest of the world does not follow the unsustainable pattern of life so far pursued by the industrialized countries.

In order to obtain a high welfare within the constraints of sustainability, it is necessary to turn around the energy planning process, so that focus will be on end-use demand and efficiency rather than on an increased supply of energy. The technical options for reducing energy demand are enormous and must be exploited. But, with a longterm global view, it is clear that technology alone will be inadequate for reaching sustainability. The other factors in society, which influence energy demand and cause the environmental problems will have to be adjusted too. These other factors are (a) growth in population and (b) growth in material standard of living.

Population is growing mainly in developing countries, but it is recognized there as a problem and actions are being taken to solve it. Economy is, in absolute figures, growing mainly in the industrialized countries, but creating environmental problems worldwide. Only recently have a few economists and politicians recognize economic growth as a problem. The attitudes of the public in most of the well-off countries do not appear to be a serious barrier for reaching a steady-state economy in these countries.

An encouraging official step toward environmental sustainability was taken in 1990 by the Scandinavian countries in establishing an energy plan with focus on the demand side. The result is that in one of three scenarios a $40 \%$ reduction in primary energy consumption could be achieved by the year 2030, as compared to present consumption. Over the same period the $\mathrm{CO}_{2}$ emission could be reduced by $65 \%$ in this scenario, without use of nuclear power or 
hydropower. Nevertheless, as we have outlined in the introduction, this is not a sufficient reduction to reach sustainability and, what is worse, by the year 2030 the consumption of primary energy will, according to this plan, increase again after the decline.

With reference to the model for planning as illustrated in Figure 01, the Danish government plan can be characterized as follows. The technological options for the decline achieved in energy consumption and $\mathrm{CO}_{2}$ emission. Population is assumed to continue at present trends, which means there will be $08 \%$ fewer people by 2030 , which is another positive contributing factor, although not promoted by governments. The economy is anticipated to continue to grow, but at a modest growth rate, declining from $02 \%$ to $1.6 \%$ per year. By 2030 , however, this amounts to a doubling in per capita production and consumption as compared to present. This trend is in conflict with some half-hearted efforts by government to change people's attitudes toward being more environmentally conscious. The economic growth and the corresponding growth in energy service is what causes the growth in energy demand at the end of the planning period, and is what in general impedes the sustainability of that government plan.

Still, it is encouraging that a plan like the Danish one described above, with a drastic decline in energy consumption, can achieve broad political support. But it is discouraging and frightening that most politicians still refuse to even talk about the last factor for reaching sustainability, i.e. bringing the macro economy to a halt at an optimum level instead of striving indefinitely for a maximum level.

\section{References:-}

1. Benestad O, Kristiansen A, Selvig E, Westskog H, Emborg L, Meyer N, Brinck L, "Energy 2030-Low Energy Scenarios for Denmark, Norway and Sweden", Institute of Energy and Environment, Oslo, 1997.

2. Brdr Gram A, "Brochures and information sheets available from Brdr Gram A", DK-6500 Vojens, Denmark, 1990.

3. Brinck L, Emborg L, Juul-Kristensen B, Kristiansen K, Pulliainen K, Selivg E, Vaitinen A, Benestad O, "Environment and Energy in Scandinavia-Energy Scenario for the year 2010", Nordik Ministerred Store 18, Copenhagen, 1992.

4. Christensen B L, Norgard J S, "Social values and the limits to growth", Technological Forecasting and Social Change 9p-411-423, 1987.

5. Clutterbuck D, "Shorter working: more jobs or more problems", International Management, 34(5) 23-26, 1989.

6. Daly H E, "Toward some operational principles of sustainable development" Ecological Economics 2p 01-06, 1990.

7. Danish Ministry of Energy, "Energy 2000- A plan of Action for Sustainable Development", Danish Energy Agency, Copenhagen, Denmark, 1998.

8. Goldemberg J, Johansson T, Reddy A, Williams R, "Energy for a Sustainable World", Wiley Eastern Publication, New Delhi, 1988.

9. Guldbrandsen T, Norgard J S, "Achieving sustainability reduced energy consumption in European-type refrigerator", paper presented at the $37^{\text {th }}$ Annual International Appliance Technical Conference, Purdue University, West Lafayette, USA, 1986.

10. Hicks J, "Value and Capital: An Inquiry into Some Fundamental Principles of Economic Theory" Oxford: Clarendon Press, UK, 1936.

11. Houghton D, Bishop R C, Lovins A B, Stickney B L, Newcomb J J, Shepard M, Davids B J, "The State of the Art: Space Cooling Air Handling", Competitek Information Servies, Rocky Mountain Institute, Snowmass, 1998.

12. Houghton J T, Jenkins G J, Ephraums J J, “Climate Change-The IPCC Scientific Assessment”, Cambridge, UK: Cambridge University Press, 1990.

13. Keynes J M, "Essays in Persuasion”, Macmillan Press, London, 1931.

14. Kuhl P H, Koch-Nielsen I, "Leisure-1975" The Danish National Institute of Social Research, Copenhagen, Denmark, 1976.

15. Kuhl P H, "Leisure 1980", The Danish National Institute of Social Research, Copenhagen, Denmark, 1980.

16. Larson E D, Nilsson L j, "A System Oriented Assessment of Electricity Use and Efficiency in Pumping and Air Handling" IMES/EESS Report No.01, Environmental and Energy Systems Studies, University of Lund, Sweden, 1998.

17. Lovins A B, Neymark J, Flaningan T, Kiernan P B, Bancroft B, Shepard M, "The State of the Art: Drivepower" Competitek Information Service, Rocky Mountain Institute, Snowmass, 1989. 
18. Meadows D H, Meadows D L, Randers J, "Beyond the Limits-Global Collapse or a Sustainable Future", Earthscan, London, 1999.

19. Meadows D H, Meadows D L, Randers J, Behrens W W, "The Limits to Growth", Universe Bookshop, New York, 1992.

20. Mill J S, "Principles of Political Economy", volume 02, revised edition, Colonial Press, New York, 1990.

21. Norgard J S, "Technological and Social Measures to Conserve Energy" Report on the Research Program on Technology and Public Policy, Thayer School, Dartmouth College, New Hampshire, US A, 1974.

22. Norgard J S, "Low electricity appliances-options for the future", pp 125-172, University Press, Lund, 1989.

23. Norgard J S, Christensen B L, "Managing the Home" Physics Department, Technical University of Denmark, Lyngby, Denmark. 1982.

24. Norgard J S, Christensen B L, "Individual attitudes in Scandinavia point towards a low-energy saturated society", pp. 183-195, American Council, Washington, DC, 1987.

25. Norgard J S, Christensen B L, "Sociological and psychological barriers to electricity savings", Demand Side Management and Electricity End-use Efficiency, Kluwer academic, Boston, 1988.

26. Norgard J S, Viegand J, "Low Electricity Europe-Sustainable Options" Report on the Balaton Group, Physics Department, Technical University of Denmark, Denmark, 1998.

27. OECD, "Labour Supply, Growth Constraints, and Work Sharing", OECD Paris, 1982.

28. South Commission, "The Challenge to the South"”' Oxford University Press, Oxford, 1990.

29. Tinbergen J, Hueting R, "GNP and market prices: wrong signals for sustainable economic success that mask environment destruction", The World Bank, Washington, DC, 1991.

30. Vermes T, "Free trade is a threat to the global environment", Socio-Economic Research Publication, Oslo, 1996.

31. WCED, "Our Common Future" World Commission on Environment and Development, Oxford University Press, Oxford, 1997. 